Article

\title{
Low-Dose-Rate Irradiation Suppresses the Expression of Cell Cycle-Related Genes, Resulting in Modification of Sensitivity to Anti-Cancer Drugs
}

\author{
Kiichi Shimabukuro ${ }^{1,2}$, Takahiro Fukazawa ${ }^{3}$, Akinori Kanai ${ }^{4,5}$, Hidehiko Kawai ${ }^{6} \mathbb{D}_{\text {, Kengo Mekata }}{ }^{1}$, \\ Nobuyuki Hirohashi ${ }^{1}$ (D), Naoya Kakimoto ${ }^{2}$ (D) and Keiji Tanimoto $^{1, *(D)}$
}

1 Department of Radiation Disaster Medicine, Research Institute for Radiation Biology and Medicine, Hiroshima University, Hiroshima 734-8553, Japan; d186571@hiroshima-u.ac.jp (K.S.); m202918@hiroshima-u.ac.jp (K.M.); hirohasi@hiroshima-u.ac.jp (N.H.)

2 Department of Oral and Maxillofacial Radiology, Graduate School of Biomedical and Health Sciences, Hiroshima University, Hiroshima 734-8553, Japan; kakimoto-n@hiroshima-u.ac.jp

3 Natural Science Center for Basic Research and Development, Hiroshima University, Hiroshima 734-8553, Japan; tfuka@hiroshima-u.ac.jp

4 Department of Molecular Oncology, Research Institute for Radiation Biology and Medicine, Hiroshima University, Hiroshima 734-8553, Japan; akkanai@edu.k.u-tokyo.ac.jp

5 Laboratory of Systems Genomics, Department of Computational Biology and Medical Sciences, Graduate School of Frontier Sciences, The University of Tokyo, Chiba 277-8562, Japan

6 Department of Nucleic Acids Biochemistry, Graduate School of Biomedical and Health Sciences, Hiroshima University, Hiroshima 734-8553, Japan; kawaih@hiroshima-u.ac.jp

* Correspondence: ktanimo@hiroshima-u.ac.jp; Tel.: +81-(0)82-257-5841; Fax: +81-(0)82-256-7105

\section{check for}

updates

Citation: Shimabukuro, K.;

Fukazawa, T.; Kanai, A.; Kawai, H.;

Mekata, K.; Hirohashi, N.; Kakimoto,

N.; Tanimoto, K. Low-Dose-Rate

Irradiation Suppresses the

Expression of Cell Cycle-Related

Genes, Resulting in Modification of

Sensitivity to Anti-Cancer Drugs.

Cells 2022, 11, 501. https://doi.org/

$10.3390 /$ cells11030501

Academic Editor: Michal Goldberg

Received: 17 December 2021

Accepted: 30 January 2022

Published: 31 January 2022

Publisher's Note: MDPI stays neutral with regard to jurisdictional claims in published maps and institutional affiliations.

Copyright: (c) 2022 by the authors Licensee MDPI, Basel, Switzerland. This article is an open access article distributed under the terms and conditions of the Creative Commons Attribution (CC BY) license (https:// creativecommons.org/licenses/by/ $4.0 /)$

\begin{abstract}
The biological effects of low-dose-rate (LDR) radiation exposure in nuclear power plant accidents and medical uses of ionizing radiation (IR), although being a social concern, remain unclear. In this study, we evaluated the effects of LDR-IR on global gene expression in human cells and aimed to clarify the mechanisms. RNA-seq analyses demonstrated that relatively low dose rates of IR modify gene expression levels in TIG-3 cells under normoxic conditions, but those effects were attenuated under hypoxia-mimicking conditions. Gene set enrichment analysis demonstrated that LDR-IR significantly decreased gene expression related to cell division, cell cycle, mitosis, and the Aurora kinase B and FOXM1 pathways. Quantitative RT-PCR confirmed the down-regulation of $A U R K B$ and FOXM1 genes in TIG-3 cells with LDR-IR or hypoxia-mimicking treatments without any dose-rate effect. Knock-down experiments suggested that HIF- $1 \alpha$ and HIF- $2 \alpha$, as well as DEC1, participated in down-regulation of $A U R K B$ and FOXM1 under DFOM treatments, but to a lesser extent under LDR-IR treatment. FACS and microscopic analyses demonstrated that LDR-IR induced G0/G1 arrest and increased micronucleus or chromosome condensation. Finally, MTT assays demonstrated that LDR-IR decreased sensitivity to paclitaxel or barasertib in TIG-3 cells but not in A549 cells. In conclusion, LDR-IR modifies global gene expression and cell cycle control, resulting in a reduction of sensitivity to anti-cancer chemotherapy in non-cancer cells and thus a reduction in untoward effects (GA).
\end{abstract}

Keywords: low-dose rate irradiation; hypoxia; $A U R K B$; FOXM1; paclitaxel

\section{Introduction}

After the nuclear power plant accidents in Chernobyl and Fukushima, the effects of low-dose-rate ionizing radiation (LDR-IR) on the human body have been a public concern. In addition, medical exposures from radiotherapy, particularly diagnostic radiology including computed tomography (CT) scanning, have been increasing year by year [1]. Many researchers have therefore been working to elucidate the effects of LDR-IR, but the specific mechanisms remain unclear [2-4]. Recently, it has been reported that the harmful 
effects caused by not only high-dose-rate irradiation (HDL-IR) but also LDR-IR increased chromosomal abnormalities that might be related to carcinogenesis [5]. On the other hand, some beneficial effects of LDR-IR have been reported, including anti-aging, biological defense activation, and anti-cancer effects [6-8]. These effects, either harmful or beneficial, can vary greatly among various cell types and are unpredictable. In general, there are several known factors that affect cellular responses to ionizing radiation; these include oxygen tension, temperature, histone configuration, and dose rate. In fact, it is well-known that a shortage of oxygen (hypoxia) plays an important role in enhancing resistance to radiation treatments [9]. We also demonstrated that hypoxic signal attenuated IR-induced DNA damage responses, including apoptosis [10]. Under hypoxia, the hypoxia-inducible transcription factors regulate gene expression related to adaptation to hypoxia, such as angiogenesis, metabolic reprograming, regulation of apoptosis, cellular differentiation, and DNA damage responses [11-13]. It has been further demonstrated that a hypoxic microenvironment and an activated hypoxic signal in various cancer cells conferred resistance to chemo-radiotherapies [14-16]. On the other hand, the effects of hypoxia on cellular responses to LDR-IR have not been elucidated. Therefore, in this study, we evaluated cellular responses to LDR-IR and the effects of hypoxia on these responses.

\section{Materials and Methods}

\subsection{Chemicals}

All chemicals were analytical grade and were purchased from FUJIFILM Wako Pure Chemicals (Osaka, Japan), Sigma-Aldrich (St. Louis, MO, USA), Selleckchem (Huston, TX, USA), or Bristol Myers Squibb (New York, NY, USA).

\subsection{Cell Culture}

Human lung fibroblast cells (TIG-3), lung adenocarcinoma cells (A549), and hepatoblastoma cells (HepG2) were purchased from The Japanese Cancer Research Resource Bank. Human breast cancer cells (MCF-7 and MDA-MB-231) were purchased from the American Type Culture Collection. Cells were maintained in Eagle's Minimum Essential Medium (MEM) or RPMI640 (NACALAI TESQUE, Inc., Kyoto, Japan) containing 10\% fetal bovine serum (FBS; BioWhittaker, Verviers, Belgium) and $100 \mu \mathrm{g} / \mathrm{mL}$ of kanamycin sulfate solution (FUJIFILM Wako Pure Chemical Corporation, Osaka, Japan). To mimic hypoxia, cells were treated with $10 \mu \mathrm{M}$ of DFOM, producing $1 \% \mathrm{O}_{2}$. The extent of DFOM treatment was set to that which activated HIF-1 and induced a target gene, CA9, in each cell type, equivalent to that under hypoxic conditions $\left(1 \% \mathrm{O}_{2}\right.$ for $\left.24 \mathrm{~h}\right)$ (Figure S1).

\subsection{Irradiation Procedure}

LDR-IR was conducted with 100,500 , or $1000 \mathrm{mGy} /$ day $(24 \mathrm{~h})$ with a ${ }^{137} \mathrm{Cs} \gamma$-ray source device (Chugai Technos Corporation, Hiroshima, Japan) for 1-7 days in each experiment. Each dose was set by adjusting the distance of the cell culture incubator $\left(37{ }^{\circ} \mathrm{C}, 5 \% \mathrm{CO}_{2}\right)$ from the radiation source. Instantaneous irradiation was performed at $800 \mathrm{mGy} / \mathrm{min}$ with a Gammacell ${ }^{\circledR} 40$ Exactor (Nordion International, Inc., Ottawa, ON, Canada) for $23-225 \mathrm{~s}$.

\subsection{Cell Proliferation and Drug Sensitivity Analyses}

Cell proliferation capacity was evaluated with the MTT assay or by counting cell numbers. Cells were seeded on a 96-well plate and cultured for 1 day, then treated with DFOM or IR for the indicated periods. For determining the $\mathrm{IC}_{50}$ values of paclitaxel (Bristol Myers Squibb) or barasertib (Selleckchem), each treatment was performed for 3 days. After incubation under the experimental treatment, the MTT (3-(4,5-dimethylthial2-yl)-2,5-diphenyltetrazalium bromide) formazan precipitate was dissolved in DMSO, and the absorbance at 570 and $650 \mathrm{~nm}$ (reference) was measured with an EMax ${ }^{\circledR}$ Endopoint ELISA Microplate Reader (Molecular Devices LLC, San Jose, CA, USA). Cell numbers were 
counted with an IN Cell Analyzer 2000 (GE Healthcare, Arlington Heights, IL, USA) after DAPI staining. All experiments were replicated at least 3 times under similar conditions.

\subsection{RNA-Seq Analysis}

Total RNA was prepared from frozen cell pellets by using NucleoSpin ${ }^{\circledR}$ RNA (MACHEREYNAGEL GmbH\&Co. KG, Düren, Germany), according to the manufacturer's instructions, and analyzed with a Bioanalyzer (Agilent Technologies, Santa Clara, CA, USA). Deep sequencing was performed by using a SureSelect Strand Specific RNA Library Prep Kit (Agilent Technologies) and HiSeq2500 (Illumina, San Diego, CA, USA) with 51 bp singleend reads at the core facility of Hiroshima University. Sequenced reads were mapped to the human genome assembly hg19 using CASAVA 1.8.2 (Illumina, RRID:SCR_001802), and read counts were normalized as reads per kilobase of exon per million mapped (RPKM). To define up-regulated or down-regulated genes, the data were trimmed by removing genes whose RPKM values were less than 2, and the relative expression between nonirradiated and irradiated cells was estimated. Genes with more than 2.0- or less than 0.5-fold expression-compared with non-irradiated cells-were identified for each differentially expressed gene. Gene set enrichment analysis was then performed on the identified genes by using Metascape (https://metascape.org/gp/index.html\#/main/step1, accessed on 24 November 2021). Overlapping genes were extracted by using jvenn, a plug-in for the jQuery javascript library (http:/ /jvenn.toulouse.inra.fr/app/index.html, accessed on 24 November 2021). These RNA sequence data have been deposited in the DNA Data Bank of Japan's Sequence Read Archive (https:/ / www.ddbj.nig.ac.jp/dra/index-e.html; Accession No: DRA012887, accessed on 18 October 2021).

\subsection{Quantitative Reverse Transcription-Polymerase Chain Reaction (RT-PCR) Analysis}

One $\mu \mathrm{g}$ of total RNA extracted from each sample was reverse-transcribed using a High-Capacity cDNA Archive ${ }^{\mathrm{TM}}$ Kit (Applied Biosystems, Waltham, MA, USA). A twohundredth aliquot of cDNA was subjected to quantitative RT-PCR with primers (final concentration $200 \mathrm{nM}$ each) and MGB probe sets (final concentration $100 \mathrm{nM}$; the Universal Probe Library [UPL], Roche Diagnostics, Basel, Switzerland) as shown in Table S1 for AURKB, FOXM1, HIF1A, EPAS1 (HIF2A), DEC1 (BHLHE40), DEC2 (BHLHE41), BAX, and $B C L 2$. The pre-developed TaqMan assay reagent (Applied Biosystems) for was used for ACTB (4326315E, Applied Biosystems) as an internal control. PCR reactions were carried out with a 7500 real-time PCR system (Applied Biosystems) under standard conditions. Gene expression levels were standardized by using pooled cDNA derived from 17 nonidentical cancer cell lines, and relative expression was calculated by using ACTB expression as the denominator for each cell line.

\subsection{Immunoblotting Analysis}

To analyze protein expression, whole cell extracts were prepared from cultured cells as previously described [13]. Fifty $\mu \mathrm{g}$ of extracts was blotted onto nitrocellulose filters following SDS-polyacrylamide gel electrophoresis. Anti-Aurora kinase B (\#3094, Cell Signaling Technology, Danvers, MA, USA) or anti- $\beta$-actin (A5441, Sigma-Aldrich) were used as primary antibodies, diluted 1:500. A 1:4000 dilution of anti-rabbit IgG or anti-mouse IgG horseradish peroxidase conjugate (\#7076, \#7074, Cell Signaling Technology) was used as a secondary antibody. Immunocomplexes were visualized by using the enhanced chemiluminescence reagent SuperSignal West Pico PLUS (Thermo Fisher Scientific, Waltham, MA, USA).

\subsection{Knock-Down Analysis}

For knock-down analysis, TIG-3 or A549 cells were transfected with siRNA specific for HIF1A (siHIF1A, SI02664053), EPAS1 (siEPAS1, SI02663038), DEC1 (siDEC1, SI00311976), or DEC2 (siDEC2, SI00312004), or with non-specific siRNA (siNS, No. 1027310) (QIAGEN, 
Inc., Valencia, CA, USA) by using Lipofectamine ${ }^{\mathrm{TM}}$ RNAiMAX (Thermo Fisher Scientific) for $24 \mathrm{~h}$. Cells were harvested and stored at $-80{ }^{\circ} \mathrm{C}$ until use.

\subsection{Plasmid Constructs and Luciferase Reporter Analysis}

Promoter regions of AURKB (1571 bp, chr17: 8,210,202-8,211,772) and FOXM1 (1145 bp, chr12: 2,877,127-2,878,271) were amplified by PCR from HepG2 genomic DNA and subcloned into the Nhe I and Xho I sites of a luciferase reporter plasmid, pGL4.26 (Promega Corporation, Madison, WI, USA). The constructs were confirmed by sequence analysis with a Big Dye Terminator Cycle Sequencing kit and an ABI 3130 Genetic Analyzer (Applied Biosystems). Details of the expression plasmid vectors of pcDNA-FLAG, pcDNA-HIF$1 \alpha$, pcDNA-HIF- $2 \alpha$, p $3 \times$ FLAG-CMV-DEC1, or p $3 \times$ FLAG-CMV-DEC2 were described previously $[17,18]$.

TIG-3 cells were seeded into 24-well plates and cultured for $24 \mathrm{~h}$. The pGL4.26-AURKB or pGL4.26-FOXM1 promoter reporter constructs $(0.2 \mu \mathrm{g}$ per well of a 24-well plate) were cotransfected with pcDNA-FLAG, pcDNA-HIF- $1 \alpha$, pcDNA-HIF- $2 \alpha$, p3 $\times$ FLAG-CMV-DEC1, or p3 $\times$ FLAG-CMV-DEC2 (0.001-0.1 $\mu$ g per well), using $0.8 \mu \mathrm{L}$ of TransIT-LT1 Transfection Reagent (Mirus Bio LLC, Madison, WI, USA). A Renilla luciferase vector (pRL-SV40, $1.0 \mathrm{ng}$ per 15-mm well) (Promega Corporation) was used as a transfection efficacy control. Cells were incubated under normoxic, DFOM-treated, or irradiated (1000 mGy/day) conditions for $24 \mathrm{~h}$ after transfection, prior to analysis of luciferase reporter activity. Luciferase luminescence was measured by using Lumat LB9507 (Berthold Technologies, Bad Wildbad, Germany).

\subsection{Cell Cycle Analysis}

The cells collected after LDR-IR or DFOM treatment, as noted above, were immediately fixed with $70 \%$ ethanol and stained with propidium iodide (PI/RNase Staining Buffer; BD Biosciences, Franklin Lakes, NJ, USA) for 15 min at room temperature in the dark. FACS analysis was then performed with LSRFortessaX-20 ${ }^{\mathrm{TM}}$ (BD Biosciences) and BD FACSDiva ${ }^{\mathrm{TM}}$ software.

\subsection{Immunofluorescence Analysis}

TIG-3 or A549 cells grown on cover slips were treated with LDR-IR (100, 500, or $1000 \mathrm{mGy} /$ day) or DFOM for 3 days. After incubation, cell nuclei were stained with 4-6-diamidino-2-phenylindole (DAPI). The subcellular distribution of fluorescence was observed and photographed with a BZ-8000 microscope (KEYENCE, Osaka, Japan). Typical images per field were selected and counted within each photograph.

\subsection{Statistical Analysis}

All of the statistical tests were performed with EZ-R version 1.54. The Tukey-Kramer method or $t$-tests were used to determine the $p$-value for post-hoc pairwise comparisons [19] when an ANOVA test revealed significant heterogeneity.

\section{Results}

\subsection{Effects of LDR-IR on Cell Proliferation}

At first, we compared sensitivity to $\gamma$-ray LDR-IR in several cell lines under normoxic conditions and found that lung fibroblast cells (TIG-3) were the most sensitive among them (Figure S2). We thus evaluated the cell proliferation capacities of TIG-3 and lung adenocarcinoma (A549) cells irradiated with LDR-IR at various dose rates $(100,500$, or $1000 \mathrm{mGy} /$ day) under normoxic or hypoxia-mimicking (DFOM) conditions (Figure 1). The cell proliferation capacity of TIG-3 cells was significantly suppressed with 1000 mGy/day of LDR-IR under normoxic conditions. That of TIG-3 cells was also suppressed with $500 \mathrm{mGy} /$ day of LDR-IR, although not significantly. On the other hand, that of A549 cells was not suppressed with LDR-IR. DFOM treatment clearly suppressed the proliferation 
capacities of both cell types used here and therefore precluded the effects of LDR-IR that were observed under normoxic conditions (Figure 1).

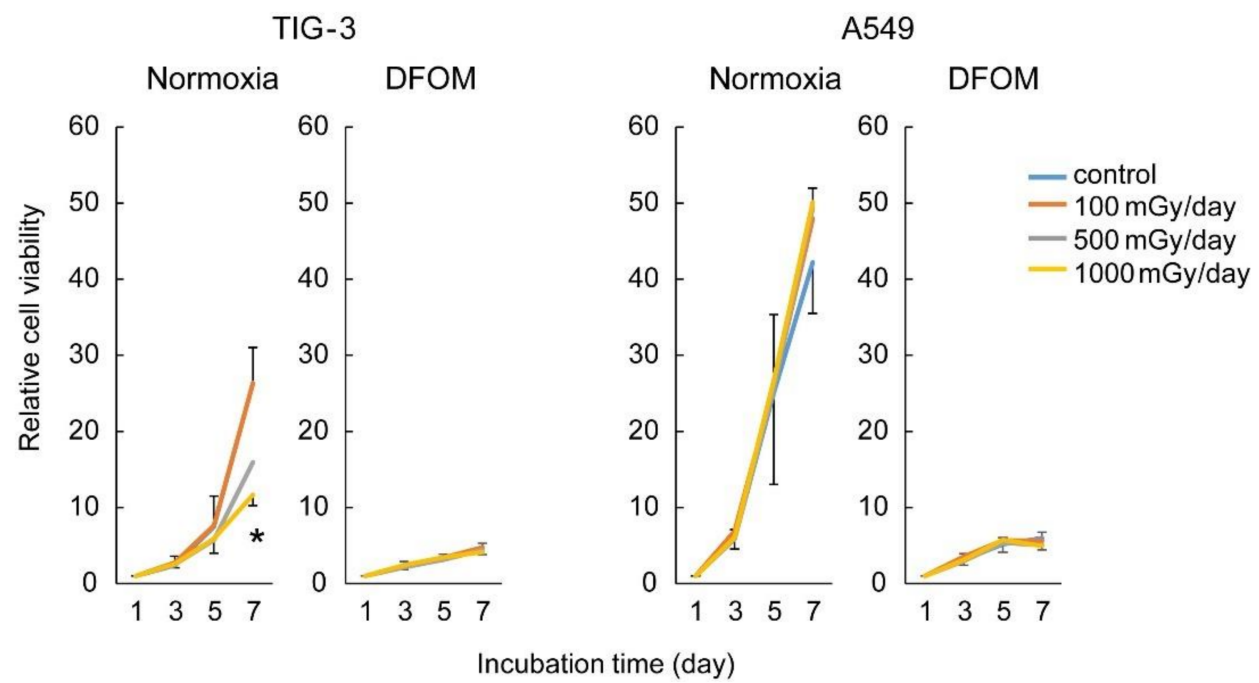

Figure 1. Effects of LDR-IR on cell proliferation. The relative cell viability of TIG-3 and A549 cells against LDR-IR under normoxic or hypoxia-mimicking (DFOM treatment) conditions was evaluated with the MTT assay. LDR-IR or DFOM treatment was started on Day 1, and the MTT assay was performed on Days 1,3, 5, and 7. Values are means and SD $(n=3){ }^{*} p<0.05$ vs. control.

\subsection{Effects of LDR-IR on Global Gene Expression}

We next evaluated the effects of the LDR-IR and DFOM treatments on global gene expression in TIG-3 cells by RNA-seq analysis. The number of genes for which expression increased to more than two-fold or decreased to less than 0.5 -fold were identified at all IR dose ranges under normoxic conditions, and the number of genes with such fold changes increased in a dose-dependent manner (expression increased in 16 genes and decreased in 15 genes with $100 \mathrm{mGy} /$ day, increased in 22 and decreased in 51 with $500 \mathrm{mGy} /$ day, and increased in 134 and decreased in 372 with $1000 \mathrm{mGy} /$ day). DFOM treatment attenuated these responses to LDR-IR (Figure 2a). Venn diagrams indicated that some of the same genes were up-regulated at different doses, but there seemed to be a change in downregulated genes above $500 \mathrm{mGy} /$ day (Figure S3). Venn diagrams also indicated that few of the same genes were also regulated after $1000 \mathrm{mGy} /$ day IR under normoxic conditions and DFOM treatment (Figure 2b,d). Gene set enrichment analysis showed that 132 genes that were specifically up-regulated after $1000 \mathrm{mGy} /$ day IR under normoxic conditions were mostly those related to functions that occur in the extracellular matrix (Figure 2c). On the other hand, 372 down-regulated genes were mostly related to cell division and cell cycle control through the Aurora kinase B and FOXM1 pathways (Figure 2e). 

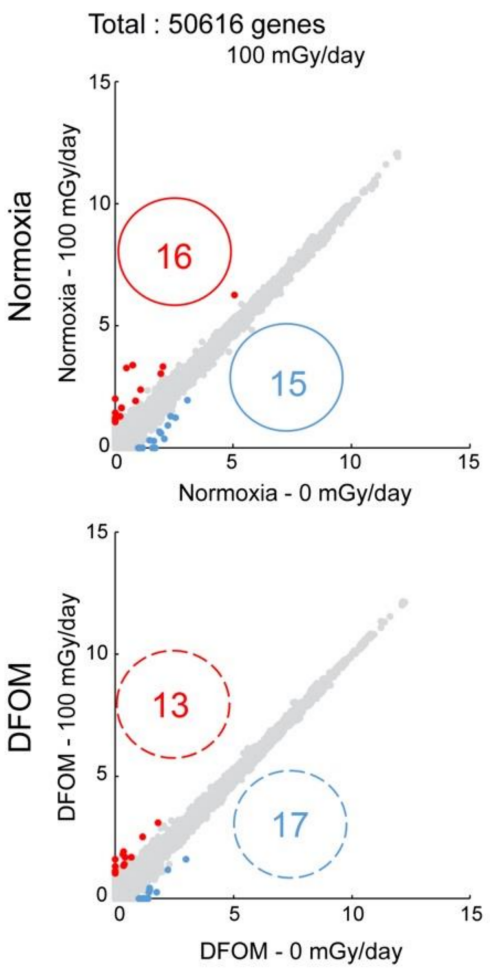
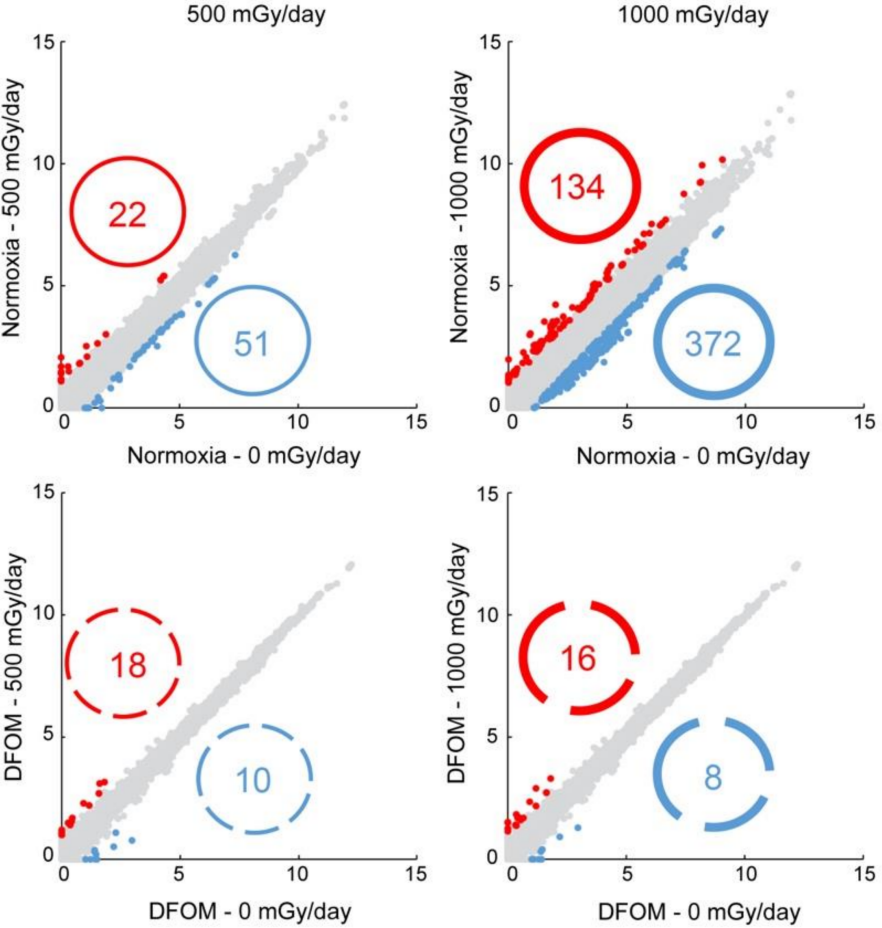

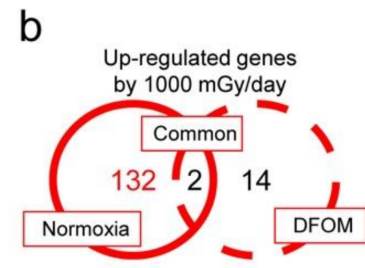

\section{d}

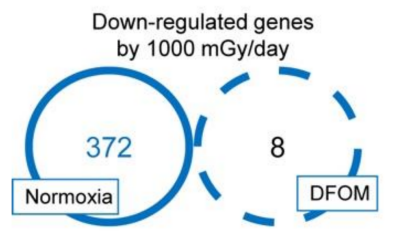

C

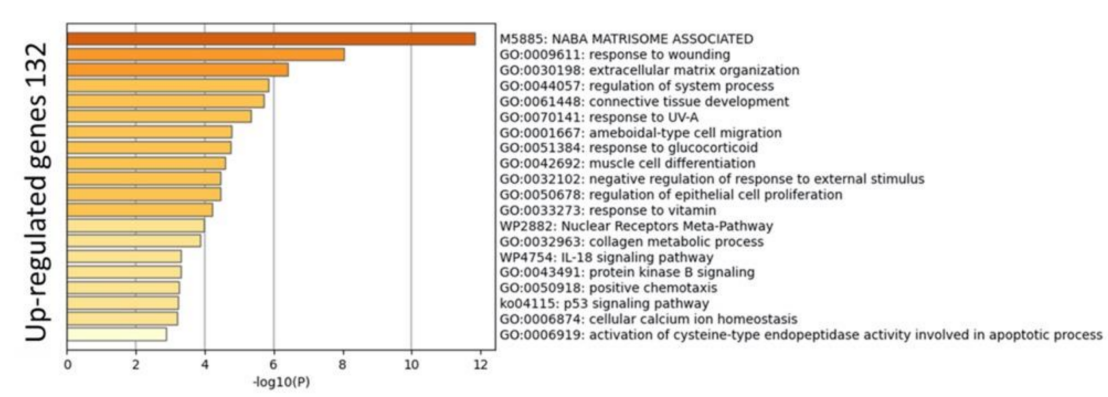

e

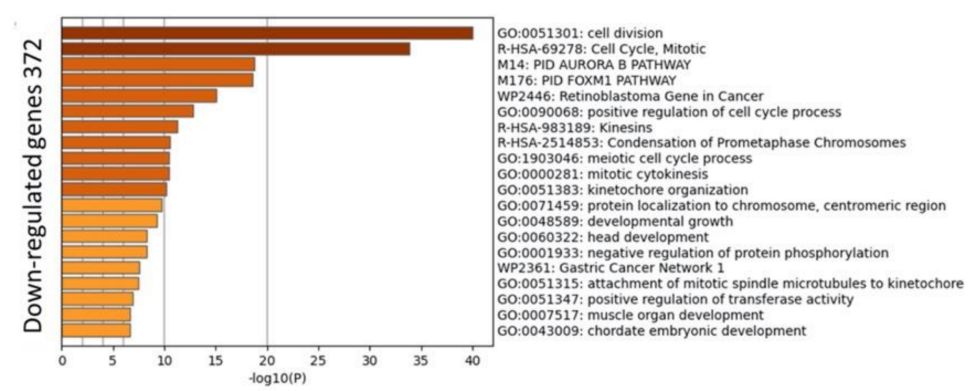

Figure 2. Effects of LDR-IR on global gene expression. (a) Gene expression levels in TIG-3 cells without or with LDR-IR under normoxic or DFOM-treated conditions were evaluated by RNA-seq. The upper three panels show the results under normoxic conditions with expression at $0 \mathrm{mGy} /$ day on the $x$-axis and expression after LDR-IR at different dose rates on the $y$-axis; the lower panels show analogous results under DFOM treatment. Red indicates up-regulation, blue indicates downregulation, and gray indicates unchanged genes (between 0.5- and 2.0-fold). Numbers in circles indicate the number of genes with modified expression levels. (b,d) Venn diagrams showing upregulated (b) or down-regulated (d) genes after $1000 \mathrm{mGy} /$ day IR under normoxia (left circle) or under DFOM treatment (right circle). (c,e) Gene set enrichment analyses were performed with Metascape. Up-regulated (c) or down-regulated (e) genes in TIG-3 cells at $1000 \mathrm{mGy} /$ day under normoxic conditions were enriched by gene ontology (GO) terms. 


\subsection{Effects of LDR-IR on Expression of AURKB and FOXM1}

Since the gene set enrichment analysis suggested that LDR-IR suppressed cell division and affected cell cycle control through the Aurora kinase B and FOXM1 pathways, respectively, we tried to evaluate the effects of LDR-IR and DFOM treatment on the expression of $A U R K B$ and FOXM1. Quantitative RT-PCR confirmed the results of RNA-seq, i.e., that the expression levels of $A U R K B$ and FOXM1 decreased significantly with LDR-IR in TIG-3 cells in a dose-dependent manner (Figure 3a). These expression levels also decreased significantly with DFOM treatment. Although it was not significant, they decreased further in TIG-3 cells with LDR-IR under DFOM, suggesting that different mechanisms might be involved in LDR-IR and DFOM treatment. The expression of AURKB also decreased in LDR-irradiated and DFOM-treated A549 cells, but the expression of FOXM1 decreased only moderately under these treatments (Figure 3a). The inhibitory effects of DFOM treatments were observed in a time-dependent manner, and the highest appeared at $72 \mathrm{~h}$ in TIG-3 and A549 cells (Figure 3b). Similar effects of IR on the expression of AURKB and FOXM1 were observed in cells instantaneously irradiated with identical total doses (Figure 3c). Down-regulation of Aurora kinase B was also confirmed by an assessment of the protein levels (Figure 3d).

\subsection{Mechanisms of Altered AURKB and FOXM1 Expression}

To clarify the mechanisms by which regulation of $A U R K B$ and FOXM1 gene expression was affected by LDR-IR or DFOM treatment, experiments were performed with knockdown of hypoxia-regulated transcription factor genes. The expression of HIF1A (HIF-1 $\alpha$ ), EPAS1 (HIF-2 $\alpha$ ), DEC1, or DEC2 genes in TIG-3 cells with LDR-IR or DFOM treatment decreased significantly after transient transfection with specific siRNA (Figure $4 a, c)$. The expression of $A U R K B$ decreased significantly in HIF1A, EPAS1, and DEC1 knock-down cells, and DFOM-induced down-regulation of $A U R K B$ was suppressed in these cells (Figure $4 \mathrm{~b}$ ). The expression of FOXM1 also decreased significantly in HIF1A, EPAS1, and DEC1 knockdown cells, and DFOM-induced down-regulation of FOXM1 was suppressed in these cells; in fact, it was up-regulated in DEC1 knock-down cells. These results suggest the involvement of HIF- $1 \alpha$, HIF- $2 \alpha$, and DEC1 in the mechanisms of DFOM-induced down-regulation. On the other hand, IR-induced down-regulation of $A U R K B$ and FOXM1 continued to be observed in HIF1A, EPAS1, DEC1, and DEC2 knock-down cells, although the decreased expression was not significant in some situations (Figure $4 \mathrm{~d}$ ). The expression of $A U R K B$ and FOXM1 in DEC2 knock-down cells increased slightly in both control and irradiated cells, suggesting some involvement of DEC2 in the mechanisms of IR-induced down-regulation. Similar results were observed in A549 cells (Figure S4). The luciferase reporter assay with subcloned $A U R K B$ and FOXM1 gene promoters further indicated HIF- $2 \alpha$ as a candidate activator of these genes in TIG-3 cells, but no other modification was observed under the DFOM or LDR-IR treatments, or with transient co-transfections (Figure S5).

\subsection{Effects of LDR-IR on the Cell Cycle and Nuclear Morphology}

Since RNA-seq and subsequent gene set enrichment analysis suggested that LDRIR suppresses cell division and cell cycle control, we evaluated the effects of LDR-IR on cell cycle regulation. Flow cytometry with PI-stained TIG-3 cells demonstrated that $1000 \mathrm{mGy} /$ day IR significantly increased the proportion of cells in the G0-G1 phase and more than $500 \mathrm{mGy} /$ day IR significantly decreased the proportion of cells in the S phase (Figure 5a). A549 cells also showed a significant increase in the proportion of cells in the G0-G1 phase after LDR-IR, and with more than $500 \mathrm{mGy} /$ day IR, the proportion in the $S$ and G2/M phases decreased significantly (Figure 5a). Under DFOM treatment, the number of cells in the G0-G1 phase decreased and the number in the S phase increased in both TIG-3 and A549 cells, with the changes being strongly evident. DFOM treatment also led to a significant increase in the number of TIG-3 cells in the G2/M phases but a decrease in the number of A549 cells in the G2/M phases. Microscopic observations with DAPI nuclear staining further demonstrated that the frequency of TIG-3 cells in the 
M phase decreased significantly with LDR-IR or DFOM treatment, whereas the number of A549 cells in the M phase showed no remarkable changes with LDR-IR and a slight decrease with DFOM treatment (Figures $5 b$ and S6). Increased numbers of micronuclei and multiple nuclei, indicating dead cells, were also observed (Figure $5 \mathrm{c}$ ). The number of micronuclei was significantly increased with LDR-IR in TIG-3 cells. A similar result was observed in A549 cells, although it was not significant. The number of dead TIG-3 cells also increased with LDR-IR, but LDR-IR did not lead to a change in the number of dead A549 cells. On the contrary, with DFOM treatment, the number of dead A549 cells increased significantly, but there was a change in the number of dead TIG-3 cells. Quantitative RTPCR indicated that BCL2 expression decreased significantly after LDR-IR in TIG-3 but not in A549 cells, resulting in reduced anti-apoptotic signals only in TIG-3 cells (Figure 5d). On the other hand, no remarkable change was observed in the expression level of $B A X$ in either cell type.

a
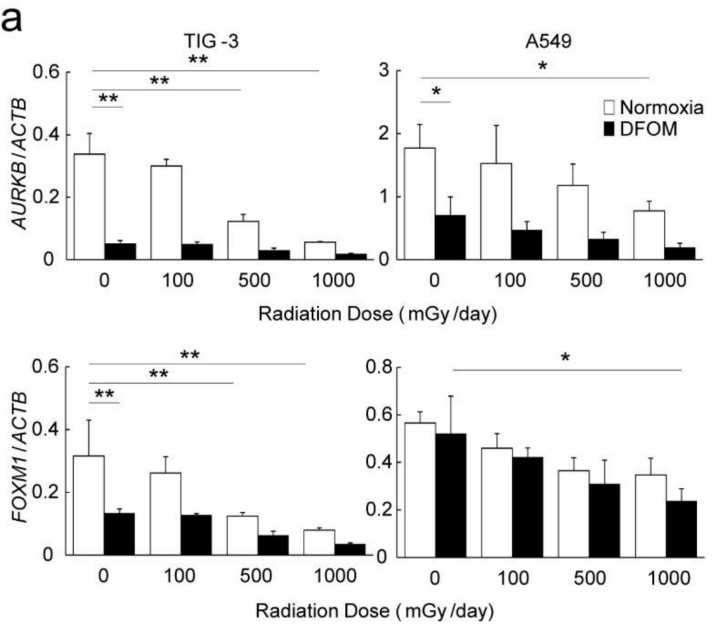

C
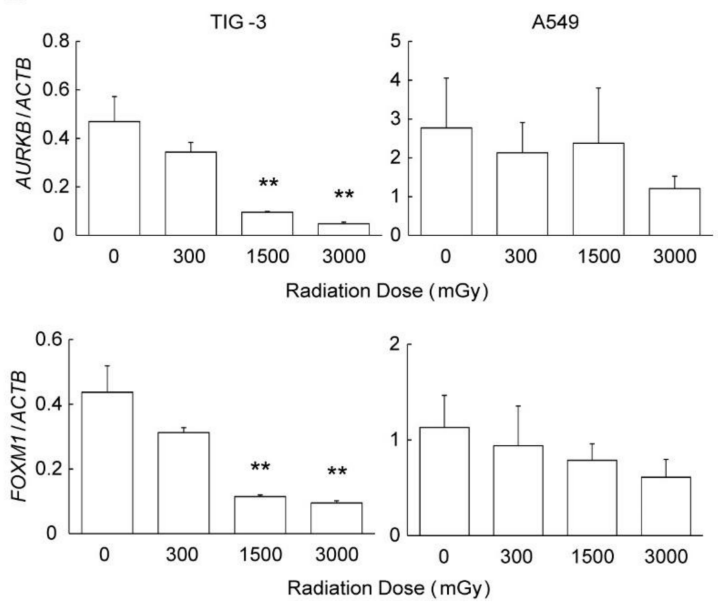

b
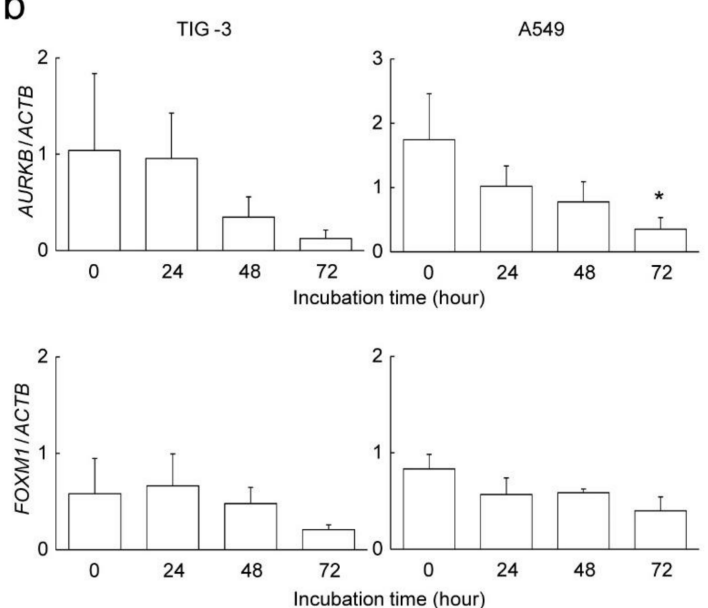

d
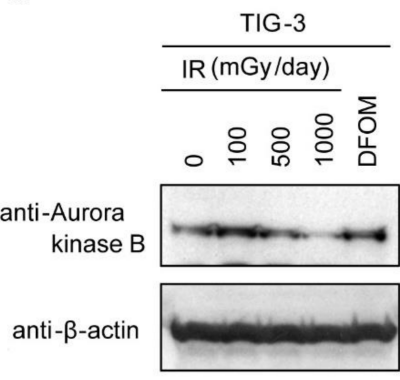

A549

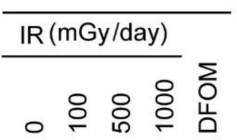

anti- $\beta$-actin

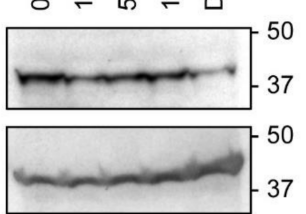

Figure 3. Effects of LDR-IR on the expression of $A U R K B$ and FOXM1. Expression levels of $A U R K B$ and FOXM1 were evaluated by quantitative RT-PCR. (a) TIG-3 and A549 cells were irradiated with 100,500 , or $1000 \mathrm{mGy}$ of $\gamma$-rays per day for 3 days under normoxic or DFOM-treated conditions. (b) Cell lines were treated with DFOM for 24, 48, and $72 \mathrm{~h}$. (c) Cell lines were irradiated with 300, 1500 , or $3000 \mathrm{mGy}$ of $\gamma$-rays, the same total doses as in the LDR-IR experiment above but with instantaneous exposure. (a-c): Relative gene expression levels were calculated as the ratio to ACTB expression. Values are represented as means and SD $(n=3) .{ }^{*} p<0.05 ;{ }^{* *} p<0.01$. (d) Protein levels of Aurora kinase B in LDR-irradiated or DFOM-treated TIG-3 and A549 cells were analyzed via immunoblotting. $\beta$-actin was used as an internal loading control. Representative images are shown from three independent experiments. 
a
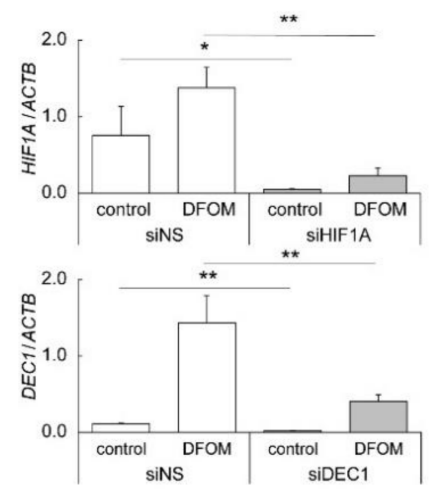

C
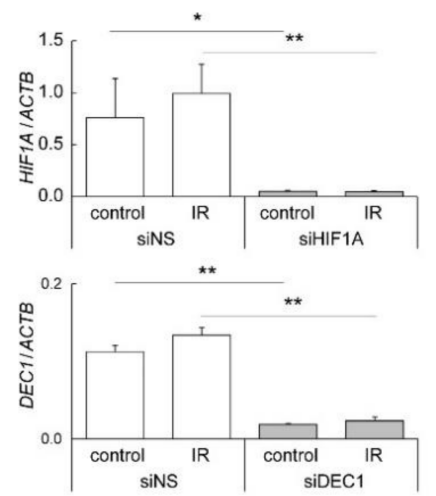

b
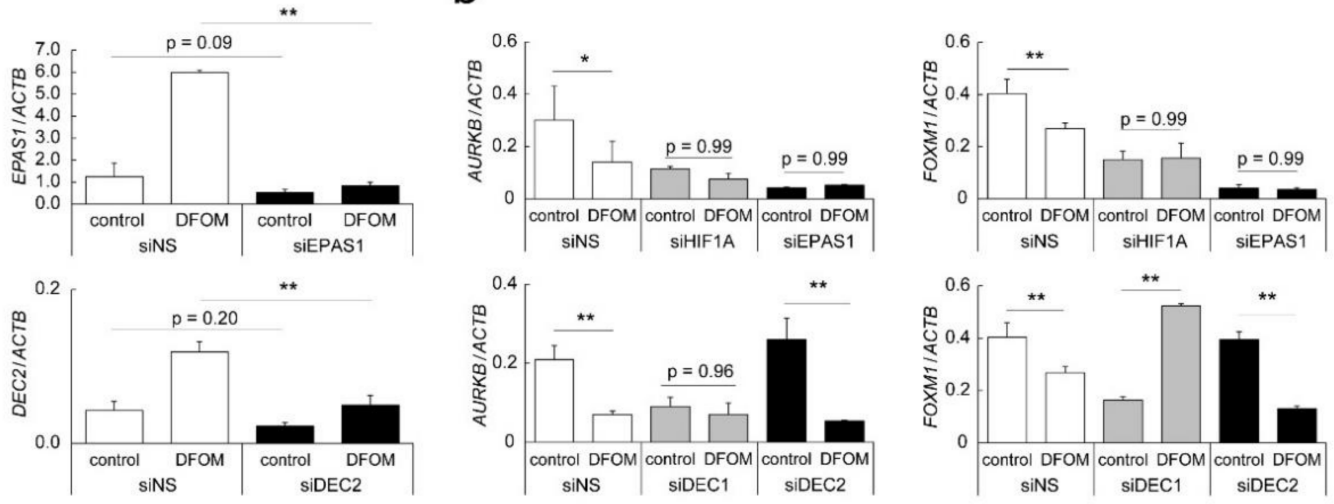

d
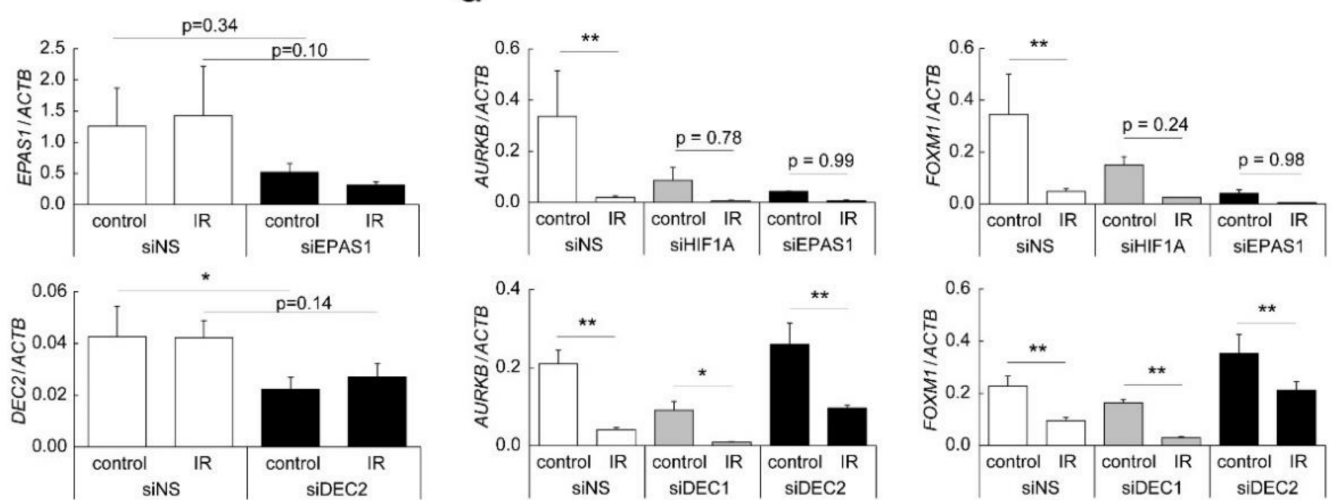

Figure 4. Regulatory mechanisms of $A U R K B$ and FOXM1 expression. Knock-down experiments were performed by using transient transfection with specific siRNA for HIF1A, EPAS1, DEC1, and DEC2. (a,c) Expression of HIF1A, EPAS1, DEC1, and DEC2 in DFOM-treated (a) or irradiated (1000 mGy/day) (c) TIG-3 cells analyzed by quantitative RT-PCR. (b,d) Expression of $A U R K B$ and FOXM1 in DFOM-treated (a) or irradiated (1000 mGy/day) (c) TIG-3 cells analyzed by quantitative RT-PCR. (a-d) Relative gene expression levels calculated as the ratio to that of ACTB. Values are means and $\mathrm{SD}(n=3)$. ${ }^{*} p<0.05 ;{ }^{* *} p<0.01$.

\subsection{Effect of LDR-IR on Sensitivity to Cell Cycle-Targeting Anti-Cancer Drugs}

Paclitaxel is in the taxane family of anti-cancer drugs and works by interfering with the function of microtubules during cell division, resulting in its efficacy as a cell cycletargeting drug $[20,21]$. Since LDR-IR modified the cell cycle distribution in TIG-3 cells, we evaluated the effect of LDR-IR on cell sensitivity to paclitaxel. MTT assays interestingly demonstrated that pre-treatment with LDR-IR before paclitaxel led to significantly reduced sensitivity to paclitaxel in TIG-3 cells only (Figure 6a). MTT assays also demonstrated reduced sensitivity to the Aurora kinase B specific inhibitor, barasertib, in TIG-3 but not in A549 cells (Figure 6a). Pre-treatment with DFOM appeared to reduce sensitivity to paclitaxel or barasertib in both TIG-3 and A549 cells (Figure 6b). Importantly, another cancer cell, HSC-2, also showed unaltered sensitivity to paclitaxel and barasertib with LDR-IR, while the sensitivity of these cells was reduced with DFOM (Figure S7). 
a

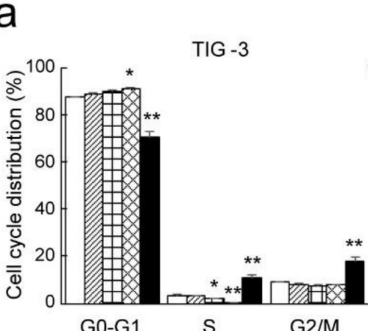

C
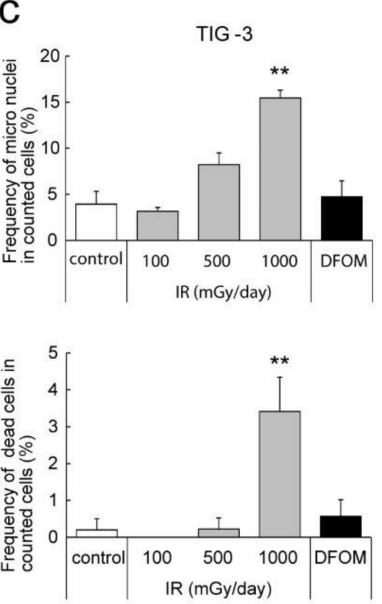

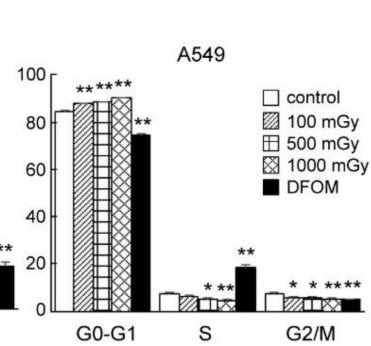

A549
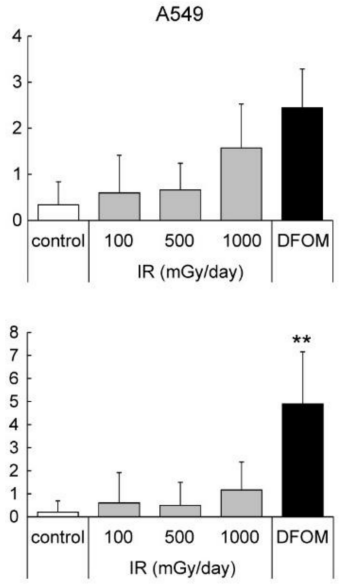

$\mathrm{b}^{\mathrm{a}}$

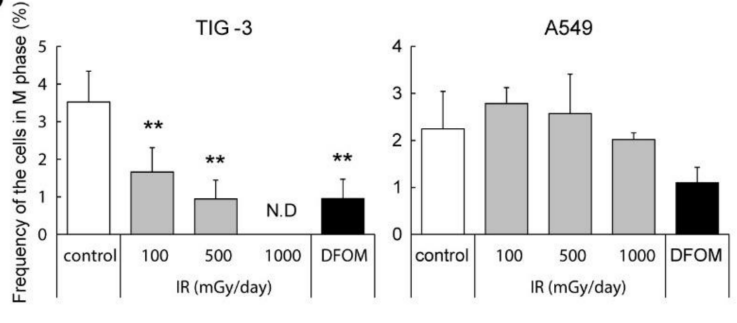

d
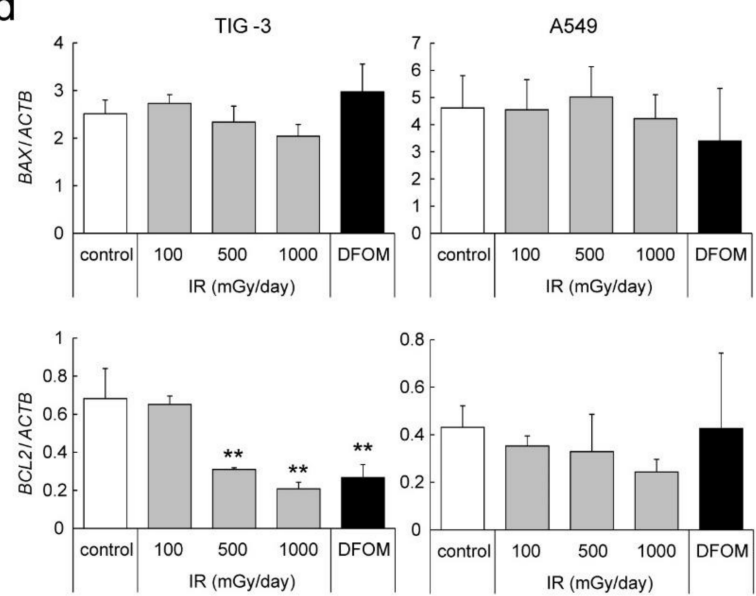

Figure 5. Effects of LDR-IR on cell cycle distribution and nuclear morphology. (a) Flow cytometry analysis was performed for evaluating the cell cycle in LDR-irradiated or DFOM-treated TIG-3 and A549 cells. (b,c) Microscopic observation was performed with DAPI nuclear staining. Frequencies of $\mathrm{M}$ phase cells (b), and micronuclei and dead cells (c). (d) Expression of BAX and BCL2 was analyzed via quantitative RT-PCR. Relative expression level was calculated as the ratio to $A C T B$ levels. (a-c) Values are means and SD $(n=3) .{ }^{*} p<0.05$ vs. control; ${ }^{* *} p<0.01$ vs. control.
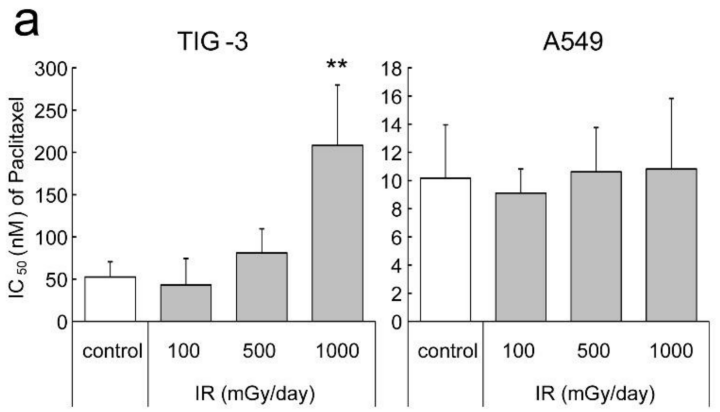

b
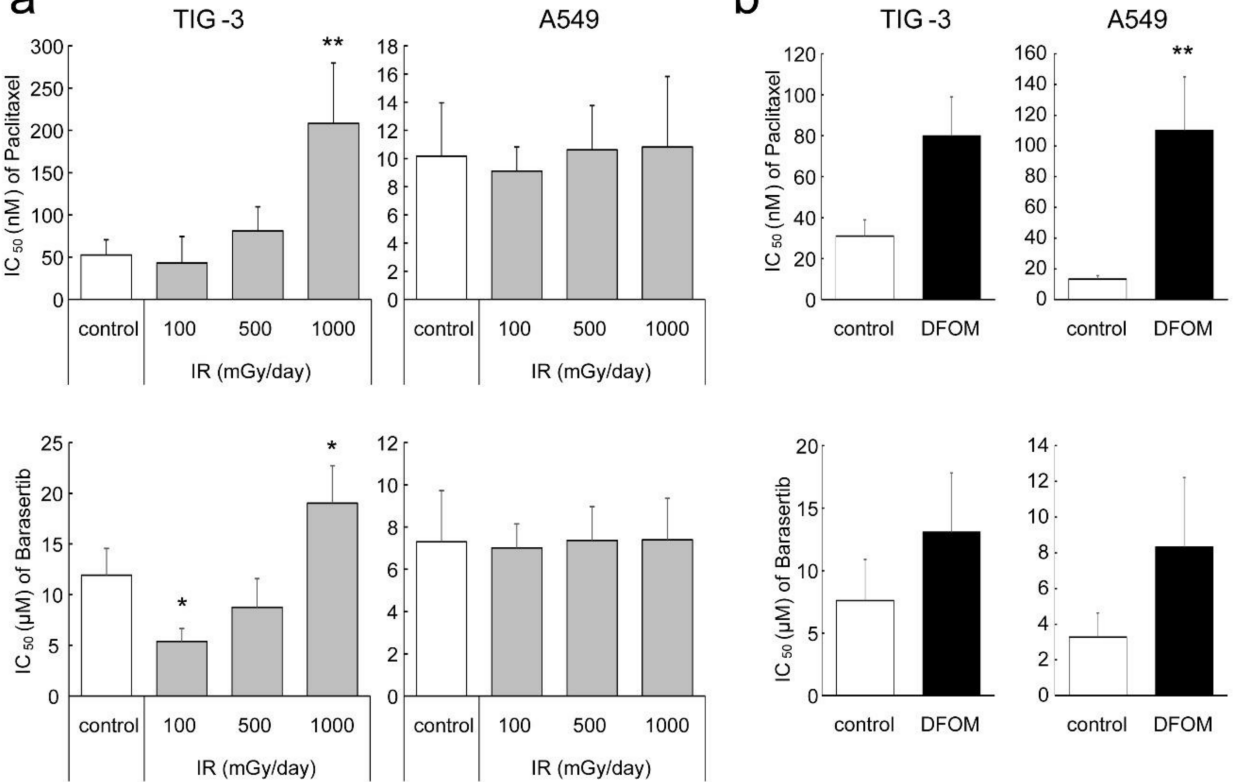

Figure 6. Effect of LDR-IR on sensitivity to cell cycle-targeting anti-cancer drugs. IC $_{50}$ values in response to paclitaxel and barasertib in TIG-3 and A549 cells pre-treated with LDR-IR $(n=4)(\mathbf{a})$ or $\operatorname{DFOM}(n=5)(\mathbf{b})$ were evaluated with the MTT assay. $(\mathbf{a}, \mathbf{b})$ Values are means and SD. ${ }^{*} p<0.05$ vs. control; ** $p<0.01$ vs. control. 


\section{Discussion}

The biological effects of low-dose-rate (LDR) radiation exposure in medical irradiation (IR) have been a source of public concern for a long time, and such concern was highlighted after the nuclear power plant accidents in Chernobyl and Fukushima. Much effort has been thus been spent on conducting studies to elucidate the mechanistic effects of LDR-IR, but much remains unclear [2-4]. In this study, we were able to elucidate some effects of LDR-IR on global gene expression and cell cycle control, resulting in useful modification of sensitivity to anti-cancer chemotherapy in a cell-specific manner.

We first evaluated the effects of relatively low-dose-rate IR on the proliferation capacity of several human cell lines, and found that lung fibroblast TIG-3 cells exhibited the greatest suppression with 500-1000 mGy/day of LDR-IR among the cells tested (Figures 1 and S2). On the other hand, lung cancer A549 cells did not exhibit such suppression with LDR-IR (Figure 1), and other cancer cell lines showed smaller effects of growth suppression than that in TIG-3 cells (Figure S2). These results suggest that a subtle IR dose rate produces cell-type-specific effects, although a larger number of cell lines should be tested. The limitation of this study is that only a few cell lines were analyzed in detail; however, that LDR-IR leads to differential regulation of proliferative capacity between normal and cancer cells was also supported by a previous study [22]. We also compared the effect of treatment with a hypoxia-mimicking reagent, DFOM, on cell proliferation but did not find any difference, suggesting that the hypoxia-mimicking reagent produced similar effects in those cells. RNA-seq analyses further demonstrated that gene expression levels were modified in TIG-3 cells after LDR-IR under normoxic conditions, in a dose-dependent manner, but those effects were strongly attenuated under hypoxia-mimicking conditions. Venn diagrams indicated that some genes were commonly up-regulated at different doses, but there seemed to be a change after $500 \mathrm{mGy} /$ day in down-regulated genes, in that few were common to widely different doses (100 and $1000 \mathrm{mGy}$; Figure S3). These results interestingly suggest that further fine-tuning of the dose rate of IR might be necessary to facilitate clarifying the detailed effects on global gene expression.

We then performed gene set enrichment analysis to study the mechanisms of regulation of gene expression involved in the LDR-IR- and hypoxia-related effects. Specifically, upregulated genes in irradiated cells mostly involved genes related to extracellular matrixrelated functions, such as response to wounding, connective tissue development, muscle cell differentiation, regulation of epithelial cell proliferation, and collagen metabolic processes (Figure 2c). These results suggest a relationship between modified gene expression and some beneficial effects of LDR-IR, including anti-aging, biological defense activation, and anti-cancer effects, which were reported previously [6-8]. On the other hand, LDR-IR was associated with a decrease in the expression of genes related to cell division, cell cycle, mitosis, and the AURORA B and FOXM1 pathways (Figure 2e). Quantitative RT-PCR further confirmed the down-regulation of $A U R K B$ and FOXM1 genes in TIG-3 cells after LDR-IR. When TIG-3 cells were exposed to the same doses of radiation instantaneously, a similar down-regulation of $A U R K B$ and FOXM1 genes was observed, suggesting that there is no dose-rate effect. Since treatment with the hypoxia-mimicking reagent DFOM attenuated the down-regulation of those genes after LDR-IR, we speculate that hypoxic signal may overcome responses to LDR-IR. In this study, LDR-IR affected $A U R K B$ and FOXM1 expression similarly in TIG-3 and A549 cells, but LDR-IR affected cell proliferation differently in these cell types (Figures 1 and 3a). It is known that ATM-mediated p53 plays an important role in the response to radiation [23]. To compare the p53 signal pathway between TIG-3 and A549 cells, a public database indicates that more mutations in p53related genes were found in A549 cells, suggesting an alteration in p53 signal (Figure S8). Further analysis of p53 signal in TIG-3 and A549 cells with LDR-IR would therefore be interesting.

The contribution of well-known hypoxia-inducible transcription factors-HIF- $1 \alpha$, HIF-2 $\alpha$, DEC1, and DEC2-to the down-regulation of AURKB and FOXM1 genes with LDR-IR as well as DFOM treatment was evaluated by using specific siRNA; we found that 
HIF- $1 \alpha$ and HIF- $2 \alpha$, as well as DEC1, might participate in the down-regulation of $A U R K B$ and FOXM1 with DFOM treatment, but not to a great extent with LDR-IR (Figure $3 \mathrm{c}$ ). In DEC2 knock-down cells, expression of $A U R K B$ and FOXM1 was slightly increased in both control and irradiated cells, suggesting some involvement of DEC2 in IR-induced down-regulation mechanisms. Promoter reporter experiments further suggested that the down-regulation of $A U R K B$ and FOXM1 gene expression after LDR-IR might not be due to transcriptional regulation, but rather to other mechanisms such as regulation of RNA stability or epigenetic regulation. There are, in fact, some reports about the relevance of promoter regulation and the $\mathrm{N}^{6}$-methyladenosine of mRNA [24-27]. Further analyses are necessary to clarify the detailed mechanisms.

Since RNA-seq and subsequent gene set enrichment analysis suggested that LDR-IR suppressed cell division and cell cycle control, we also evaluated the effects of LDR-IR on cell cycle regulation. After LDR-IR, the G0-G1 population size increased, whereas the S and G2/M population sizes decreased, in both TIG-3 and A549 cells, suggesting activation of the G1/S checkpoint (Figure 5a). Microscopic observations, however, indicated decreased mitosis in TIG-3 but not A549 cells, suggesting that regulation of the G2/M transition under LDR-IR differs between those two cell types. DFOM treatment strongly decreased the G0-G1 population size and increased the S population size in both TIG-3 and A549 cells. DFOM interestingly increased the G2/M population size in TIG-3 cells but decreased it in A549 cells, also suggesting differential regulation of cell cycle checkpoints: activation of the M phase checkpoint in TIG-3 cells but the S phase checkpoint in A549 cells. These results suggest that LDR-IR and hypoxic signaling regulate the cell cycle in a cell-typespecific manner. The majority of double-strand breaks (DSBs) are repaired through nonhomologous end-joining (NHEJ) in somatic cells. However, homologous recombination repair (HRR) is known to be enhanced in embryonic cells [28], in which it is invoked predominantly during the S and G2 phases [29,30]. NHEJ is also reported to act in the G1 and early $S$ phases in vertebrate cells [31,32]. In this study, regulation of the G2/M transition by LDR-IR was suggested to differ between TIG-3 and A549 cells. Since the TIG-3 cell line is derived from embryos, LDR-IR might predominantly affect HRR, resulting in inhibition of the G2/M transition.

Microscopic observations indicated increased micronuclei in LDR-irradiated TIG-3 cells (Figure 5c). LDR-IR also significantly increased the number of dead TIG-3 cells but not of A549 cells, although the proportions of dead cells were small (Figure 5c). That BCL2 expression was down-regulated by LDR-IR only in TIG-3 cells further supports these observations (Figure 5d). These results suggest that LDR-IR actually induces DNA damage and subsequent cell cycle arrest, resulting in suppressed proliferation of TIG-3 cells. Since we observed the cells for only 3 days after IR in this study, the long-term effects could not be evaluated, so longer observations are desired.

Finally, we investigated whether LDR-IR affected the sensitivity of anti-cancer drugs targeting the cell cycle or Aurora kinase B, and interestingly found that pre-treatment with LDR-IR significantly reduced the sensitivity to paclitaxel or barasertib in TIG-3 but not in A549 cells. On the other hand, DFOM pre-treatment reduced sensitivity to both drugs in both cells (Figure 6b). The molecular mechanisms of these results remain unclear, but one possible explanation is that LDR-IR significantly decreased the M phase of TIG-3 but not A549 cells. Furthermore, DFOM treatment decreased the number of cells in the M phase in both cell types. Such differential regulation of the cell cycle might allow for the differential control of sensitivity to paclitaxel, allowing its cytotoxic effects to be better focused on cancer cells and less damaging to healthy cells. Some reports suggested that the AURKB gene is involved in the mechanisms of susceptibility to paclitaxel for NSCLC, susceptibility to cetuximab for head and neck SCC, and susceptibility to vemurafenib for melanoma, and that FOXM1 is involved in susceptibility to paclitaxel or herceptin for breast cancer [33-36]. Taken together, our results demonstrate that LDR-IR modifies chemo-sensitivity through the regulation of genes related to these anti-cancer-treatment mechanisms. 
In summary, we clarified the effects of LDR-IR on cell cycle control through the cell-type-specific regulation of $A U R K B$ and FOXM1 gene expression. On that basis, we were able to suggest a promising chemo-radiation protocol combining LDR-IR and cell cycle-targeting anti-cancer drugs. Further investigation is necessary to clarify the detailed mechanisms and to develop effective radiological protection or anti-cancer treatments.

Supplementary Materials: The following supporting information can be downloaded at https:// www.mdpi.com/article/10.3390/cells11030501/s1. Figure S1: Optimization of the DFOM treatments in TIG-3 and A549 cells. Figure S2: Effects of LDR-IR on cell proliferation. Figure S3: Venn diagram of the differentially expressed genes in LDR-irradiated cells. Figure S4: Regulation mechanisms of $A U R K B$ and FOXM1 gene expressions in A549. Figure S5: Effects of LDR-IR, DFOM treatment, or co-transfection with hypoxia-regulated transcription factor genes on AURKB and FOXM1 promoter activities. Figure S6: Effects of LDR-IR on nuclear morphology. Figure S7: Effect of LDR-IR on sensitivity to cell cycle-targeting anti-cancer drugs in HSC-2 cells. Figure S8: Venn diagram illustrating the mutation spectrum of p53-related genes in A549 and TIG-3 cells. Table S1: Primer and probe sets for quantitative RT-PCR.

Author Contributions: Conceptualization, K.T.; methodology, K.T.; software, H.K. and A.K.; validation, K.S., T.F. and K.T.; formal analysis, K.S. and K.M.; investigation, K.S.; resources, H.K., A.K. and K.T.; data curation, K.S. and K.M.; writing-original draft preparation, K.S.; writing-review and editing, T.F. and K.T.; visualization, T.F.; supervision, K.T.; project administration, N.K., N.H. and K.T.; funding acquisition, N.K. and K.T. All authors have read and agreed to the published version of the manuscript.

Funding: This work was partly supported by a Grants-in-Aid for Scientific Research (C) awarded by the Japan Society for the Promotion of Science (No. 23592766).

Institutional Review Board Statement: Not applicable.

Informed Consent Statement: Not applicable.

Data Availability Statement: The data that support the findings of this study are openly available in the DNA Data Bank of Japan's Sequence Read Archive (https:/ / www.ddbj.nig.ac.jp/dra/index-e. html; Accession No: DRA012887, accessed on 18 October 2021).

Acknowledgments: The authors thank Chiyo Oda (Hiroshima University) for her technical support. Part of this work was carried out at the Analysis Center of Life Science at Hiroshima University.

Conflicts of Interest: The authors declare no conflict of interest.

\section{References}

1. de González, A.B.; Darby, S. Risk of cancer from diagnostic X-Rays: Estimates for the UK and 14 other countries. Lancet 2004, 363, 345-351. [CrossRef]

2. Samet, J.M.; Niwa, O. At the 75th Anniversary of the bombings of Hiroshima and Nagasaki, the radiation effects research foundation continues studies of the atomic bomb survivors and their children. Carcinogenesis 2020, 41, 1471-1472. [CrossRef] [PubMed]

3. Yeager, M.; Machiela, M.J.; Kothiyal, P.; Dean, M.; Bodelon, C.; Suman, S.; Wang, M.; Mirabello, L.; Nelson, C.W.; Zhou, W.; et al. Lack of transgenerational effects of ionizing radiation exposure from the Chernobyl accident. Science 2021, 372, 725-729. [CrossRef]

4. $\quad$ Morton, L.M.; Karyadi, D.M.; Stewart, C.; Bogdanova, T.I.; Dawson, E.T.; Steinberg, M.K.; Dai, J.; Hartley, S.W.; Schonfeld, S.J.; Sampson, J.N.; et al. Radiation-related genomic profile of papillary thyroid carcinoma after the Chernobyl accident. Science 2021, 372, eabg2538. [CrossRef] [PubMed]

5. Imano, N.; Nishibuchi, I.; Kawabata, E.; Kinugasa, Y.; Shi, L.; Sakai, C.; Ishida, M.; Sakane, H.; Akita, T.; Ishida, T.; et al. Evaluating individual radiosensitivity for the prediction of acute toxicities of chemoradiotherapy in esophageal cancer patients. Radiat. Res. 2020, 195, 244-252. [CrossRef]

6. Le Bourg, É. Hormesis, aging and longevity. Biochim. Biophys. Acta (BBA) Gen. Subj. 2009, 1790, 1030-1039. [CrossRef]

7. Rühm, W.; Azizova, T.V.; Bouffler, S.D.; Little, M.P.; Shore, R.E.; Walsh, L.; Woloschak, G.E. Dose-rate effects in radiation biology and radiation protection. Ann. ICRP 2016, 45, 262-279. [CrossRef]

8. Barsoumian, H.B.; Ramapriyan, R.; Younes, A.I.; Caetano, M.S.; Menon, H.; Comeaux, N.I.; Cushman, T.R.; Schoenhals, J.E.; Cadena, A.P.; Reilly, T.P.; et al. Low-dose radiation treatment enhances systemic antitumor immune responses by overcoming the inhibitory stroma. J. Immunother. Cancer 2020, 8, e000537. [CrossRef] 
9. Semenza, G.L. Intratumoral hypoxia, radiation resistance, and HIF-1. Cancer Cell 2004, 5, 405-406. [CrossRef]

10. Nakamura, H.; Bono, H.; Hiyama, K.; Kawamoto, T.; Kato, Y.; Nakanishi, T.; Nishiyama, M.; Hiyama, E.; Hirohashi, N.; Sueoka, E.; et al. Differentiated embryo chondrocyte plays a crucial role in DNA damage response via transcriptional regulation under hypoxic conditions. PLoS ONE 2018, 13, e0192136. [CrossRef]

11. Wang, G.L.; Jiang, B.-H.; Rue, E.A.; Semenza, G.L. Hypoxia-inducible Factor 1 Is a Basic-Helix-Loop-Helix-PAS heterodimer regulated by cellular 02 tension. Proc. Natl. Acad. Sci. USA 1995, 5, 5510-5514. [CrossRef]

12. Forsythe, J.A.; Jiang, B.H.; Iyer, N.V.; Agani, F.; Leung, S.W.; Koos, R.D.; Semenza, G.L. Activation of vascular endothelial growth factor gene transcription by hypoxia-inducible factor 1. Mol. Cell. Biol. 1996, 16, 4604-4613. [CrossRef]

13. Shimamoto, K.; Tanimoto, K.; Fukazawa, T.; Nakamura, H.; Kanai, A.; Bono, H.; Ono, H.; Eguchi, H.; Hirohashi, N. GLIS1, a novel hypoxia-inducible transcription factor, promotes breast cancer cell motility via activation of WNT5A. Carcinogenesis 2020, 41, 1184-1194. [CrossRef]

14. Wilson, W.R.; Hay, M.P. Targeting hypoxia in cancer therapy. Nat. Rev. Cancer 2011, 11, 393-410. [CrossRef]

15. Cairns, R.; Papandreou, I.; Denko, N. Overcoming physiologic barriers to cancer treatment by molecularly targeting the tumor microenvironment. Mol. Cancer Res. 2006, 4, 61-70. [CrossRef] [PubMed]

16. Horsman, M.R.; Overgaard, J. The impact of hypoxia and its modification of the outcome of radiotherapy. J. Radiat. Res. 2016, 57, i90-i98. [CrossRef] [PubMed]

17. Khalesi, E.; Nakamura, H.; Lee, K.L.; Putra, A.C.; Fukazawa, T.; Kawahara, Y.; Makino, Y.; Poellinger, L.; Yuge, L.; Tanimoto, K. The Krüppel-like Zinc finger transcription factor, GLI-Similar 1, is regulated by hypoxia-inducible factors via non-canonical mechanisms. Biochem. Biophys. Res. Commun. 2013, 441, 499-506. [CrossRef] [PubMed]

18. Nakamura, H.; Tanimoto, K.; Hiyama, K.; Yunokawa, M.; Kawamoto, T.; Kato, Y.; Yoshiga, K.; Poellinger, L.; Hiyama, E.; Nishiyama, M. Human mismatch repair gene, MLH1, is transcriptionally repressed by the hypoxia-inducible transcription factors, DEC1 and DEC2. Oncogene 2008, 27, 4200-4209. [CrossRef]

19. Kanda, Y. Investigation of the freely available easy-to-use software 'EZR' for medical statistics. Bone Marrow Transpl. 2013, 48, 452-458. [CrossRef] [PubMed]

20. Weaver, B.A. How Taxol/Paclitaxel kills cancer cells. MBoC 2014, 25, 2677-2681. [CrossRef] [PubMed]

21. Wani, M.C.; Taylor, H.L.; Wall, M.E.; Coggon, P.; McPhail, A.T. Plant antitumor agents. VI. Isolation and structure of taxol, a novel antileukemic and antitumor agent from Taxus Brevifolia. J. Am. Chem. Soc. 1971, 93, 2325-2327. [CrossRef] [PubMed]

22. Cao, L.; Kawai, H.; Sasatani, M.; Iizuka, D.; Masuda, Y.; Inaba, T.; Suzuki, K.; Ootsuyama, A.; Umata, T.; Kamiya, K.; et al. A novel ATM/TP53/P21-mediated checkpoint only activated by chronic $\gamma$-irradiation. PLoS ONE 2014, 9, e104279. [CrossRef] [PubMed]

23. Stewart-Ornstein, J.; Iwamoto, Y.; Miller, M.A.; Prytyskach, M.A.; Ferretti, S.; Holzer, P.; Kallen, J.; Furet, P.; Jambhekar, A.; Forrester, W.C.; et al. P53 dynamics vary between tissues and are linked with radiation sensitivity. Nat. Commun. 2021, 12, 898. [CrossRef] [PubMed]

24. Zhang, X.; Wang, F.; Wang, Z.; Yang, X.; Yu, H.; Si, S.; Lu, J.; Zhou, Z.; Lu, Q.; Wang, Z.; et al. ALKBH5 promotes the proliferation of renal cell carcinoma by regulating AURKB expression in an M6A-dependent manner. Ann. Transl. Med. 2020, 8, 646. [CrossRef] [PubMed]

25. Chao, Y.; Shang, J.; Ji, W. ALKBH5-M6A-FOXM1 signaling axis promotes proliferation and invasion of lung adenocarcinoma cells under intermittent hypoxia. Biochem. Biophys. Res. Commun. 2020, 521, 499-506. [CrossRef]

26. Zhang, S.; Zhao, B.S.; Zhou, A.; Lin, K.; Zheng, S.; Lu, Z.; Chen, Y.; Sulman, E.P.; Xie, K.; Bögler, O.; et al. M 6 a demethylase ALKBH5 maintains tumorigenicity of glioblastoma stem-like cells by sustaining FOXM1 expression and cell proliferation program. Cancer Cell 2017, 31, 591-606.e6. [CrossRef]

27. Xia, L.-M.; Huang, W.-J.; Wang, B.; Liu, M.; Zhang, Q.; Yan, W.; Zhu, Q.; Luo, M.; Zhou, Z.-Z.; Tian, D.-A. Transcriptional up-regulation of FoxM1 in response to hypoxia is mediated by HIF-1. J. Cell. Biochem. 2009, 106, 247-256. [CrossRef] [PubMed]

28. Valerie, K.; Povirk, L.F. Regulation and mechanisms of mammalian double-strand break repair. Oncogene 2003, $22,5792-5812$. [CrossRef]

29. Haber, J.E. Partners and pathways. Trends Genet. 2000, 16, 259-264. [CrossRef]

30. Morrison, C. The controlling role of ATM in homologous recombinational Repair of DNA damage. EMBO J. 2000, $19,463-471$. [CrossRef]

31. Lee, S.E.; Mitchell, R.A.; Cheng, A.; Hendrickson, E.A. Evidence for DNA-PK-dependent and -independent DNA double-strand break repair pathways in mammalian cells as a function of the cell cycle. Mol. Cell. Biol. 1997, 17, 1425-1433. [CrossRef] [PubMed]

32. Takata, M.; Sasaki, M.S.; Sonoda, E.; Morrison, C.; Hashimoto, M.; Utsumi, H.; Yamaguchi-Iwai, Y.; Shinohara, A.; Takeda, S. Homologous recombination and non-homologous end-joining pathways of DNA double-strand break repair have overlapping roles in the maintenance of chromosomal integrity in vertebrate cells. EMBO J. 1998, 17, 5497-5508. [CrossRef] [PubMed]

33. Al-Khafaji, A.S.; Davies, M.P.; Risk, J.M.; Marcus, M.W.; Koffa, M.; Gosney, J.R.; Shaw, R.J.; Field, J.K.; Liloglou, T. Aurora B Expression modulates paclitaxel response in non-small cell lung cancer. Br. J. Cancer 2017, 116, 592-599. [CrossRef] [PubMed]

34. Hoellein, A.; Pickhard, A.; von Keitz, F.; Schoeffmann, S.; Piontek, G.; Rudelius, M.; Baumgart, A.; Wagenpfeil, S.; Peschel, C.; Dechow, T.; et al. Aurora kinase inhibition overcomes cetuximab resistance in squamous cell cancer of the head and neck. Oncotarget 2011, 2, 599-609. [CrossRef] [PubMed] 
35. Phadke, M.S.; Sini, P.; Smalley, K.S.M. The novel ATP-competitive MEK/Aurora Kinase inhibitor BI-847325 overcomes acquired BRAF inhibitor resistance through suppression of Mcl-1 and MEK expression. Mol. Cancer Ther. 2015, 14, 1354-1364. [CrossRef] [PubMed]

36. Carr, J.R.; Park, H.J.; Wang, Z.; Kiefer, M.M.; Raychaudhuri, P. FoxM1 Mediates resistance to Herceptin and paclitaxel. Cancer Res. 2010, 70, 5054-5063. [CrossRef] 